\title{
Adapting focused antenatal care: Lessons from three African countries
}

Harriet Birungi

Population Council

Follow this and additional works at: https://knowledgecommons.popcouncil.org/departments_sbsr-rh

Part of the Demography, Population, and Ecology Commons, Family, Life Course, and Society Commons, Gender and Sexuality Commons, International Public Health Commons, Maternal and Child Health Commons, Medicine and Health Commons, and the Women's Health Commons How does access to this work benefit you? Let us know!

\section{Recommended Citation}

Birungi, Harriet. 2008. "Adapting focused antenatal care: Lessons from three African countries," FRONTIERS Program Brief. Washington, DC: Population Council. 


\section{Adapting Focused Antenatal Care: Lessons from Three African Countries}

n 2001 the World Health Organization (WHO) issued guidance on a new model of antenatal care (ANC) called goal-oriented or focused antenatal care (FANC), for implementation in developing countries (Villar et al. 2001). The new model reduces the number of required antenatal visits to four, and provides focused services shown to improve maternal outcomes. FANC eliminates the traditional risk assessments and instead emphasizes helping women to maintain normal pregnancies by identifying existing health conditions, detecting emerging complications, promoting health, preparing for a healthy birth, and educating clients on postpartum care including nutrition, breastfeeding, and family planning. Trials conducted in Argentina, Cuba, Saudi Arabia, and Thailand proved that FANC was safe and was a more sustainable, comprehensive, and effective ANC model (WHO 2001).

In response to this evidence, several countries in subSaharan Africa ${ }^{1}$ moved to adapt FANC as a way of pro-

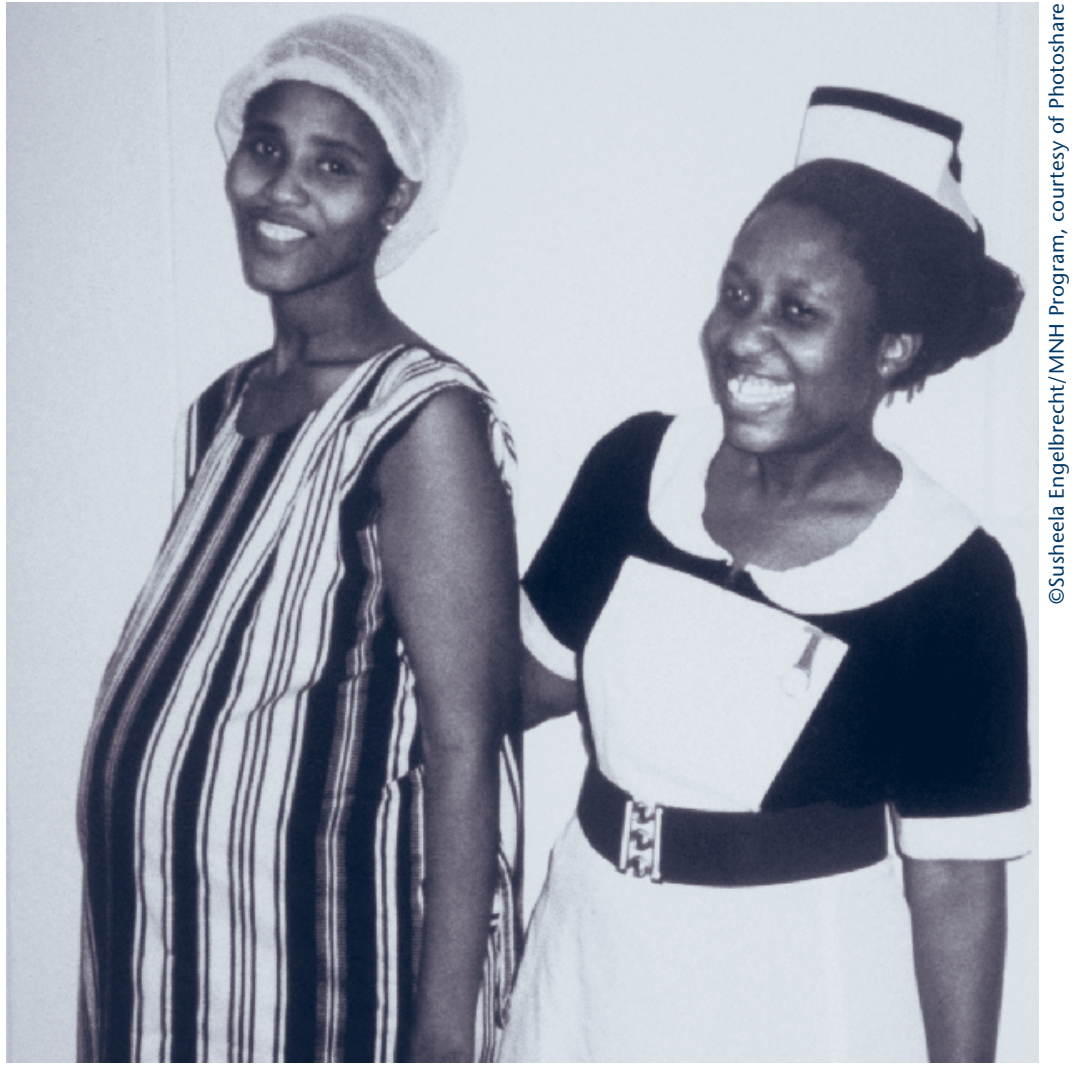

A pregnant woman with a health worker in Ghana.

moting the health and survival of mothers and babies. However, the feasibility of implementing the FANC approach in this setting and the changes in policy and program requirements needed

${ }^{1}$ Kenya, Tanzania, Uganda, Ghana, South Africa, Malawi, Zambia, Zimbabwe (Armar-Klemusu et al. 2006). are not well understood. This Program Brief describes findings from operations research conducted by the Frontiers in Reproductive Health Program (FRONTIERS) to assess the feasibility, acceptability, and effects of implementing FANC in Ghana, Kenya, and South Africa.

FANC is acceptable to clients and providers in Africa, and can improve quality of care. However, sustainable provision of FANC requires the following:

- Staff training, including training strategies that address staff attrition.

- Outreach to ensure client compliance.

- Infrastructure strengthening to ensure availability of space, equipment, and supplies for providing services. 


\section{Assessing FANC in sub-Saharan Africa}

Many countries in subSaharan Africa now require pregnant women to make a maximum of four visits during which programs are directed to provide a set of essential interventions for each visit (see Box). ANC is also an opportunity to promote the use of skilled attendance at delivery and healthy behaviors such as breastfeeding, early postnatal care, and postpartum family planning for limiting or spacing births. However, studies have shown that there are many missed opportunities for care, both because of client- and health system-related factors. Mothers and children may face risks because of limited or late-term ANC visits, low-quality care during visits due to poor provider training, infrastructure and administrative weakness at facilities, complications of existing conditions such as TB, malaria, anemia, or sexually transmitted infections (STIs), and short intervals between births (ArmarKlemusu et al. 2006; Birungi and Onyango-Ouma 2006; Chege et al. 2005).

\section{FANC services}

Generally, providing FANC entails a range of services including the following:

- History taking on current complaints, dietary history, reproductive history, tetanus vaccination status, and review of danger signs.

- Screening for malaria, syphilis, and TB.

- Physical examination including general health assessment, check for STIs, pre-eclampsia, anemia, and fetal growth.

- Provision of iron, folate, antimalarials, and tetanus toxoid.

- Client counseling on individual birth plan, complication readiness, nutrition and return date, and postpartum use of family planning.

- Laboratory investigation for hemoglobin, grouping and rhesus factor, screening and testing for syphilis, sickle cell, TB, hepatitis B (if indicated), and HIV.

Thus, the introduction and scale-up of FANC in sub-Saharan Africa makes demands on health systems that are already stressed. Countries implementing FANC will need to cost and assess the effect of the FANC service package in terms of its content, coverage, affordability, and sustainability of services over time.

The challenge to most subSaharan African countries is to formulate application of the WHO FANC model within country needs and resources and identify the best approaches to deliver effective and sustainable FANC. This requires countries to respond to certain key questions:

- How should services be reorganized to ensure delivery of a comprehensive, integrated package?

- What systems capacity is required to offer the package?

- What services should be included in the package?

- Does the package contribute to improved quality of care, and which components require strengthening over time?

- Is FANC acceptable to clients and providers?

\section{Contents}

\begin{tabular}{lr} 
Assessing FANC in & \\
\multicolumn{1}{c}{ sub-Saharan Africa } & 2 \\
Key lessons & 10 \\
Conclusions & 11 \\
References & 11
\end{tabular}

Assessing FANC in 
To this end, FRONTIERS conducted studies in Ghana, Kenya, and South Africa to examine the requirements for implementing FANC in these settings, assessed whether the public health systems were capable of adapting FANC for sustainable implementation, and the effect of FANC on the quality of care provided. These three studies bring together key lessons that are useful for countries planning to introduce FANC in sub-Saharan Africa.

The quality and content, acceptability, and sustainability of the Ghana and Kenya programs were assessed using an integrated case study design, which incorporated policy and situation analyses, at the national and regional level (ArmarKlemusu et al. 2006; Birungi and Onyango-Ouma 2006). In South Africa, FRONTIERS pilottested introduction of a FANC protocol in 2001 (Chege et al. 2005) and prospectively studied its feasibility and effectiveness in two districts through a quasiexperimental design, with health facilities offering ANC services as sampling units. Interviews at baseline and endline were conducted with providers, clients, client-provider interaction observations, and clinic inventories.

The introduction of FANC required training for providers, logistical planning to ensure reliable availability of drugs and supplies, and infrastructure adjustments to change the process of care and to provide a physical space and a functioning laboratory. National Reproductive Health Service Policy and Standards and maternal health cards in all three countries were revised to reflect the changes in ANC.

\section{FANC in Ghana}

In Ghana, reproductive health policy and ANC guidelines were revised to include early detection and treatment of all complications arising during pregnancy. Emphasis was also laid on assessing birth preparedness and complication readiness, prevention of malaria in pregnancy and of mother-to-child transmission of HIV (PMTCT). The ANC schedule was reduced from 13 visits to four comprehensive, personalized ANC visits. FANC was introduced at Tema General Hospital through an initiative by JHPIEGO and served as a model for the Ministry of Health. Here, existing ANC services were reinvigorated by carrying out three major interventions:

- Introducing focused ANC job aids such as charts and posters.

- Introducing integrated services, including history taking, physical and laboratory examinations (blood and urine test, measurement of blood pressure, weight, height, and temperature), counseling on all health problems, behaviors, minor discomforts of pregnancy, danger signs, birth preparedness, counseling and testing for HIV, and postpartum family planning.

- Ensuring that the same provider attends the client during all four ANC visits.

\section{Frontiers in Reproductive Health} Program Brief No. 11

Author: Harriet Birungi

Editor: Stephanie Joyce

Design: Vincent Hughes Visualization

We appreciate the assistance and contributions of the following reviewers: Ian Askew, Patricia Stephenson.

Suggested citation: Birungi, Harriet. 2008. "Adapting focused antenatal care in three African countries," FRONTIERS Program Brief No. 11. Washington, DC: Population Council.

The photos on pages 1 and 11 were selected from Photoshare at www.photoshare.org

The Frontiers in Reproductive Health Program (FRONTIERS) applies systematic research techniques to improve delivery of family planning and reproductive health services and influence related policies. FRONTIERS is funded by the U.S. Agency for International Development (USAID) and led by the Population Council in collaboration with Family Health International.

This publication is made possible by the generous support of the American people through the United States Agency for International Development (USAID) under the terms of Cooperative Agreement No. HRN-A-00-98-00012-00. The contents are the responsibility of the FRONTIERS Program and do not necessarily reflect the views of USAID or the United States Government.

(C) 2008 The Population Council, Inc.

This publication may be reproduced in whole or in part without permission of the Population Council provided full source citation is given and the reproduction is not for commercial purposes.

ISSN 1546-6612 


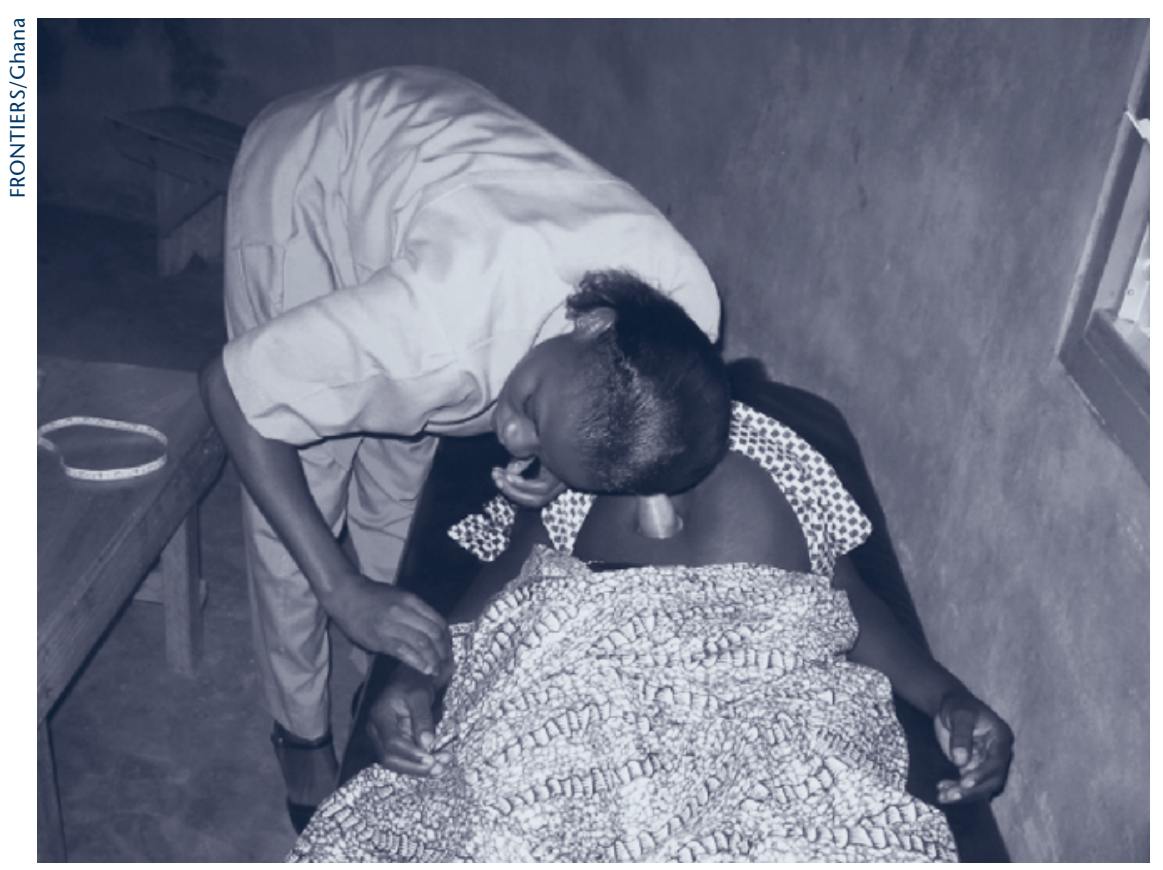

A provider examines a client in Ghana.

In addition, ANC services were reorganized from an assemblyline type of model, in which clients would need to see as many as six providers during one consultation, to an individualized package of care from one provider. This ensured that the same providers attended to the same client during first and subsequent visits. In addition, Maternal and Child Health Units were refurbished to provide quality ANC. Each midwife received a fully furnished consulting cubicle to provide personalized care to the client.

\section{FANC in Kenya}

Kenya introduced the comprehensive FANC service package as recommended by $\mathrm{WHO}$, with additional components to respond to national health needs. The new components included PMTCT, intermittent presumptive treatment of malaria, developing an individual birth plan, TB screening, detection and treatment, and education on various topics, including rest, nutrition, and exercise in pregnancy, breastfeeding information, family planning, and planning for postpartum care. Guidelines specified the appropriate times for providing specific services and education-for example, measuring blood pressure and education on nutrition at all four visits; and assessing the fetal position and providing information on family planning at the third and fourth visits.
Research informed the FANC introduction process, and FANC was first pilot-tested as a joint FANC and malaria in pregnancy intervention in 2001 in two districts, and subsequently replicated in 19 malaria-endemic districts in 2002. In-service training of service providers was an essential component in introducing FANC, and was supported by JHPIEGO with funding from the U.K. Department for International Development. Staff were trained through the cascade approach and included the provincial health management teams, district health management teams, and finally teams of providers at the facilities. Kenya also invested heavily in developing job aids, including tools to screen for malaria and $\mathrm{TB}$, fatherto-be checklists, an ANC physical exam checklist, and a pamphlet for developing an individual birth plan.

Introduction of FANC in Kenya also included community sensitization, which initially involved short messages about FANC to pregnant mothers through morning educational sessions held at maternity and family planning clinics. The educational sessions consisted of group health talks and individual messages given by providers before and during service delivery. This approach was found to be ineffective in sensitizing community members, however, as it only targeted clients who sought services at clinics. Consequently, a community orientation manual was developed to sensitize communities 
about the key changes (for example, that pregnant women would only be expected to visit the clinics for four comprehensive visits, instead of 13 visits as was the previous practice) and to enlist the support of opinion leaders, men, and family members during the pregnancy. The manual was used in public meetings as a way to inform communities about changes in the delivery of ANC services. However, findings from focus group discussions suggested that coverage was limited to opinion leaders.

\section{FANC in South Africa}

To improve the quality of ANC provided at the clinics in South Africa, the Maternal, Child and Women's Health Unit of the KwaZulu-Natal Department of Health (KZN DOH) collaborated with FRONTIERS to review and revise its ANC guidelines on the basis of WHO's model of focused ANC. They developed a comprehensive checklist for FANC that consisted of five goal-directed ANC visits and two postnatal care visits. The revised package included the routine services that were already recommended by WHO and additional services that were felt to be important during specific visits. The focused package aimed to provide comprehensive ANC services by integrating the following services into routine ANC service provision:

\section{- STI prevention counseling,} diagnosis, and management using the syndromic approach.
- Onsite syphilis screening using the rapid plasma reagin (RPR) test. All first visit ANC clients should have their blood drawn for onsite syphilis screening and receive their results the same day.

- HIV prevention information, including PMTCT, and referral for voluntary counseling and testing (VCT) either within the clinic or at a referral hospital (where VCT was not available onsite).

- Active promotion of family planning as a means of preventing maternal mortality in high-parity women.

An assessment of necessary drugs, equipment, and supplies was undertaken during the planning stages, and all missing essential equipment and supplies were subsequently provided. Providers also received in-service training on the service package through the cascade training approach that used educational modules. The KZN DOH identified master trainers, who were primary health care (PHC) supervisors, PHC trainers, and advanced midwives or professional nurses experienced in antenatal care in the intervention district. The master trainers were expected to train the nurses immediately after completing the modules, and so there was a break of two weeks after completion of each module (apart from RPR testing) to allow the master trainers to "cascade" the skills learned during each module to the clinics. Areas covered during training included:
- Reducing visits to five antenatal and two postnatal, with each visit entailing a set number of stipulated activities.

- Conducting assessments for prevention, screening for, and management of health conditions likely to increase the risk of adverse pregnancy outcomes (monitoring blood pressure and weight, clinical exam to detect early warning signs, urinalysis and microscopy of urine, immunization against tetanus, iron and folic acid supplements).

- Screening and managing STIs using the syndromic approach.

- Conducting individualized and group counseling and health education sessions on the physiological processes of pregnancy and childbirth, recognizing pregnancy risk factors and appropriate health seeking behavior, appropriate nutrition, personal hygiene and exercise, STIs and HIV prevention behaviors including PMTCT and VCT, and postpartum family planning.

- Discussing and developing a delivery plan.

- Providing a referral for VCT, if needed.

- Conducting onsite syphilis testing using RPR tests. 


\section{Is FANC acceptable to clients and service providers?}

Both providers and clients found FANC acceptable. Providers in all three countries appreciated the comprehensiveness of the package. FANC had no detrimental effect on staff morale, because improvements in clinic preparedness to offer ANC services reduced some concerns about working conditions. In Ghana, clients liked FANC because it offered them the opportunity to receive individualized care and reduced the number of provider contacts.

However, FANC seems to have created longer waiting times in Kenya, which was unac- ceptable to many clients. Most clients spent one to two hours waiting for ANC services in the intervention clinics, while in the comparison clinics most clients spent 30 to 45 minutes. The longer waiting time could be due to poor organization of the new services and their configuration, which needs to be explicitly considered whenever FANC is introduced. Clients in Kenya were also concerned about the informal fees being charged for the FANC services. Government policy states that clients should receive ANC services free of charge, but about half of clients were charged between Kshs10 - 120 (US\$0.10 - \$1.60) for lab fees, medicines, a "devel- opment fund," registration cards, or other services, which raised the overall cost of ANC.

\section{Does FANC improve the quality of antenatal care services?}

In Kenya and Ghana, quality of care was measured using a scale aggregating scores from indicators of five key components of focused ANC: (1) comprehensive history taking; (2) detection of existing diseases and management of complications; (3) prevention of disease and promotion of health; (4) planning for birth and prevention of complications; (5) postpartum care; and (6) encouraging continuity of care. The scores were

Table 1.

\section{Changes in quality of care during four ANC visits at intervention and control clinics in Kenya}

\begin{tabular}{|c|c|c|c|c|c|c|c|c|}
\hline & \multicolumn{4}{|c|}{ Intervention Clinics } & \multicolumn{4}{|c|}{ Control Clinics } \\
\hline & $\begin{array}{l}\text { Visit } 1 \\
\text { Score } \\
(0-5)\end{array}$ & $\begin{array}{l}\text { Visit } 2 \\
\text { Score } \\
(0-4)\end{array}$ & $\begin{array}{l}\text { Visit } 3 \\
\text { Score } \\
(0-5)\end{array}$ & $\begin{array}{l}\text { Visit } 4 \\
\text { Score } \\
(0-5)\end{array}$ & $\begin{array}{l}\text { Visit } 1 \\
\text { Score } \\
(0-5)\end{array}$ & $\begin{array}{l}\text { Visit } 2 \\
\text { Score } \\
(0-4)\end{array}$ & $\begin{array}{l}\text { Visit } 3 \\
\text { Score } \\
(0-5)\end{array}$ & $\begin{array}{l}\text { Visit } 4 \\
\text { Score } \\
(0-5)\end{array}$ \\
\hline $\begin{array}{l}\text { Comprehensive } \\
\text { history taking }\end{array}$ & 0.36 & - & - & - & 0.33 & - & - & - \\
\hline $\begin{array}{l}\text { Detection of diseases } \\
\text { and management of } \\
\text { complications }\end{array}$ & $0.50^{* *}$ & $0.67^{*}$ & 0.60 & 0.40 & $0.34^{\star *}$ & $0.54^{*}$ & 0.57 & 0.40 \\
\hline $\begin{array}{l}\text { Prevention of disease } \\
\text { and promotion of health }\end{array}$ & 0.25 & 0.19 & 0.12 & 0.10 & 0.31 & 0.18 & 0.12 & 0.11 \\
\hline $\begin{array}{l}\text { Preparation for birth \& } \\
\text { potential complications }\end{array}$ & $0.24^{* *}$ & $0.26^{* *}$ & $0.28^{* *}$ & $0.06^{* *}$ & $0.04^{* *}$ & $0.04^{* *}$ & $0.05^{* *}$ & $0.06^{* *}$ \\
\hline $\begin{array}{l}\text { Counseling on } \\
\text { postpartum care }\end{array}$ & - & - & $0.04^{* *}$ & $0.03^{*}$ & - & - & $0.00 * *$ & $0.00^{*}$ \\
\hline $\begin{array}{l}\text { Encouraging } \\
\text { continuity of care }\end{array}$ & 0.69 & 0.66 & 0.67 & 0.67 & 0.64 & 0.64 & 0.63 & 0.62 \\
\hline Total performance & $2.04^{* *}$ & $1.78^{* *}$ & $1.71^{* *}$ & $1.26^{* *}$ & $1.66^{* *}$ & $1.40 * *$ & $1.37^{* *}$ & $1.19 * *$ \\
\hline
\end{tabular}

${ }^{*} \mathrm{p}<0.05 ;{ }^{* *} \mathrm{p}<0.01 ;-=$ Not Applicable

Source: Birungi and Onyango-Ouma 2006 
Table 2.

\section{Changes in quality of care during four ANC visits at intervention and control clinics in Ghana}

\begin{tabular}{|c|c|c|c|c|c|c|c|c|}
\hline & \multicolumn{4}{|c|}{ Intervention Clinics } & \multicolumn{4}{|c|}{ Control Clinics } \\
\hline & $\begin{array}{l}\text { Visit } 1 \\
\text { Score } \\
(0-5)\end{array}$ & $\begin{array}{l}\text { Visit } 2 \\
\text { Score } \\
(0-4)\end{array}$ & $\begin{array}{l}\text { Visit } 3 \\
\text { Score } \\
(0-4)\end{array}$ & $\begin{array}{l}\text { Visit } 4 \\
\text { Score } \\
(0-4)\end{array}$ & $\begin{array}{l}\text { Visit } 1 \\
\text { Score } \\
(0-5)\end{array}$ & $\begin{array}{l}\text { Visit } 2 \\
\text { Score } \\
(0-4)\end{array}$ & $\begin{array}{l}\text { Visit } 3 \\
\text { Score } \\
(0-4)\end{array}$ & $\begin{array}{l}\text { Visit } 4 \\
\text { Score } \\
(0-4)\end{array}$ \\
\hline $\begin{array}{l}\text { Comprehensive } \\
\text { history taking }\end{array}$ & 0.62 & - & - & - & 0.68 & - & - & - \\
\hline $\begin{array}{l}\text { Detection of diseases } \\
\text { and management of } \\
\text { complications }\end{array}$ & 0.47 & 0.50 & 0.56 & $0.57^{* *}$ & 0.51 & 0.44 & 0.51 & $0.48^{* *}$ \\
\hline $\begin{array}{l}\text { Prevention of disease and } \\
\text { promotion of health }\end{array}$ & $0.24^{*}$ & $0.22^{\star \star}$ & $0.18^{*}$ & 0.17 & $0.16^{*}$ & $0.12^{\star *}$ & $0.13^{*}$ & 0.13 \\
\hline $\begin{array}{l}\text { Preparation for birth \& } \\
\text { potential complications }\end{array}$ & 0.14 & 0.10 & 0.10 & 0.11 & 0.14 & 0.09 & 0.07 & 0.14 \\
\hline $\begin{array}{l}\text { Counseling on } \\
\text { postpartum care }\end{array}$ & - & - & 0.03 & 0.02 & - & - & 0.00 & 0.00 \\
\hline $\begin{array}{l}\text { Encouraging continuity } \\
\text { of care }\end{array}$ & $0.80^{* *}$ & $0.82^{\star *}$ & $0.82^{* *}$ & $0.81^{*}$ & $0.70^{* *}$ & $0.74^{* *}$ & $0.70^{* *}$ & $0.74^{*}$ \\
\hline Total performance & 2.27 & $1.64^{* *}$ & $1.69^{* *}$ & $1.67^{*}$ & 2.19 & $1.41^{* *}$ & $1.40 * *$ & $1.50 *$ \\
\hline
\end{tabular}

${ }^{*} \mathrm{p}<0.05 ;{ }^{* *} \mathrm{p}<0.01 ;-=$ Not Applicable

Source: Armar-Klemusu et al. 2006

generated from observations of client-provider interactions during four ANC visits, and a mean score was computed for each component and for each visit. These numbers were then compared using statistical significance tests between intervention and comparison clinics.

The introduction of FANC had a positive effect on the overall quality of ANC in both countries. In Kenya, a highly significant effect was noted in detection of existing diseases in pregnancy during the first ANC visit, planning for delivery and prevention of complications, and counseling for postpartum care (see Table 1). No effect was found, however, in comprehensive history taking, disease prevention, health promotion, or consultation to encourage continuity in care. While a greater proportion of providers in both countries advised clients to use postpartum family planning (13\% and $18 \%$, respectively, compared to zero at the control clinics) during the third visit, this proportion declined by the fourth visit (to $3 \%$ and $8 \%$ ). Also, despite improvements, the quality of care remained substandard, especially for the third and fourth visits.

In Ghana, as in Kenya, the quality of care remained less than acceptable, although clients visiting intervention clinics where FANC had been introduced received higher quality of care than in comparison clinics (see Table 2). Across the six FANC components, better quality of care was noted in disease prevention (malaria and anemia in pregnancy), promotion of health (counseling on STIs and HIV), 
and continuity of care. Clients visiting clinics where FANC was introduced received more comprehensive care than those visiting comparison clinics. Clients were also offered individualized care, especially continuous care under one nurse, with better client-provider interactions and improved privacy and confidentiality. Half of the clients seen at the intervention clinics had only one provider contact, compared to less than a quarter in the comparison group.

In South Africa there was no overall difference between the FANC clinics and the status quo, because of immediate staff turnover and inadequate supervision in these clinics. Because staff were either not replaced, or their replacements were not trained in the new ANC model, it was not possible or valid to determine whether or not implementation of the intervention improved the quality of care. This is because, following its introduction, staffing problems meant that the intervention could not be implemented as intended. While both intervention and comparison clinics performed well before and after the intervention in terms of conducting physical checkups (weight, blood pressure, urinalysis, and fetal heartbeat, for example), indicators on other FANC elements, such as education on birth preparedness, breastfeeding, pregnancy danger signs, and family planning, were low and lagged behind those of the comparison clinics. The proportion of providers discussing family planning decreased

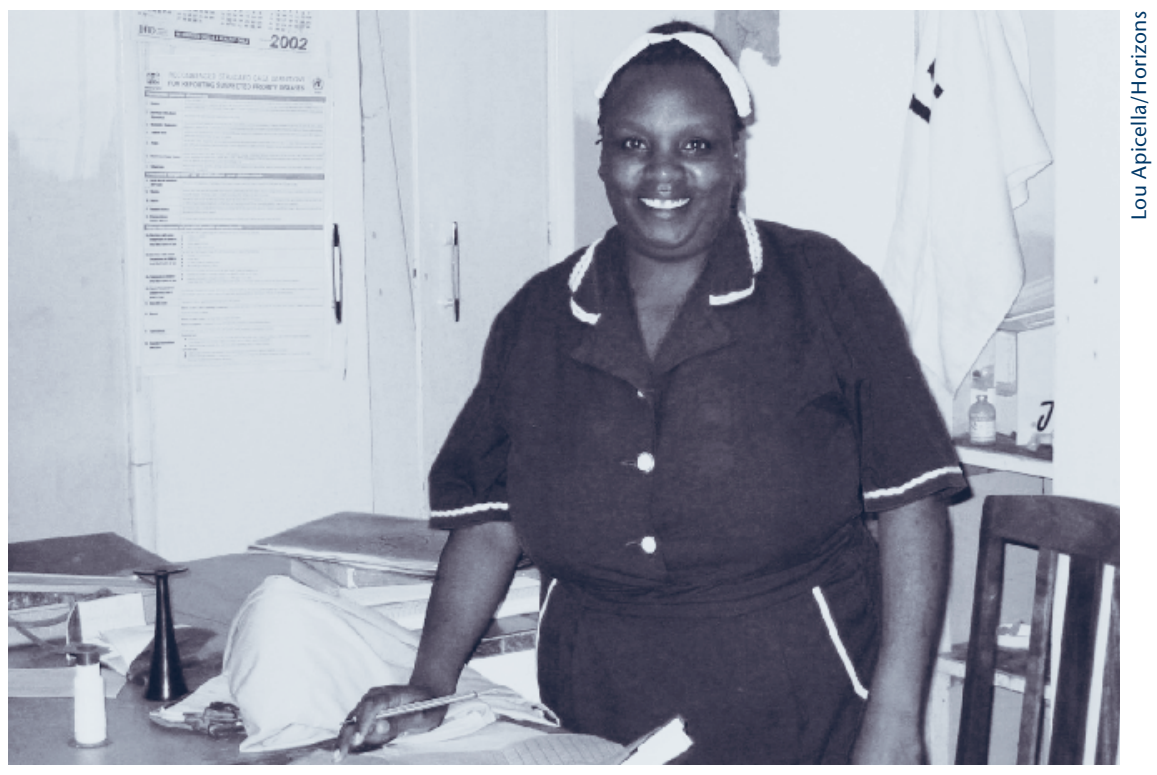

A nurse in Katani, Kenya.

significantly at the intervention clinics between baseline and endline (from $43 \%$ to $29 \%$ ), while increasing significantly at the comparison clinics (from 32\% to $52 \%)$.

The introduction of FANC did, however, increase the likelihood that providers in the intervention clinics would discuss STI and HIV services. At endline, the proportion of providers who recommended condom use for STI prevention increased from 15 percent to 45 percent, remaining at about 20 percent in control clinics. A significantly greater proportion of clients in the intervention clinics reported that providers had discussed HIV services at endline compared to clients in the comparison sites (see Table 3). However, the propor-

Table 3.

\section{Proportion of first visit clients receiving HIV-related information or services in South Africa}

\begin{tabular}{|c|c|c|c|c|}
\hline & \multicolumn{2}{|c|}{ Intervention } & \multicolumn{2}{|l|}{ Control } \\
\hline & $\begin{array}{l}\text { Baseline } \\
(n=59)\end{array}$ & $\begin{array}{l}\text { Endline } \\
(n=53)\end{array}$ & $\begin{array}{l}\text { Baseline } \\
(\mathrm{n}=65)\end{array}$ & $\begin{array}{l}\text { Endline } \\
(n=49)\end{array}$ \\
\hline Discussed PMTCТ & 17 & $36^{*}$ & 9 & $31^{* *}$ \\
\hline Discussed advantages of VCT & 17 & 30 & 17 & 32 \\
\hline Discussed where to get VCT & 10 & $32^{* *}$ & 23 & 29 \\
\hline Clients referred for VCT & 2 & 11 & 6 & 13 \\
\hline $\begin{array}{l}\text { Received at least one } \\
\text { HIV service }\end{array}$ & 20 & 42 & 26 & 37 \\
\hline
\end{tabular}


tions of women receiving these services remained well below the coverage expected. Particularly worrying is that less than onethird of pregnant women were informed about PMTCT and VCT, even though the rollout of the national PMTCT program coincided with this intervention. Moreover, the additional services provided in the intervention clinics primarily included an external genital exam, discussion of STI symptoms, and condom use for STI prevention. There was no increase in assessing a client's personal risk for STIs, including presence of symptoms (although these assessments did increase in the comparison clinics).

In 2004, the KZN DOH requested the assistance of FRONTIERS in the development of standardized guidelines, policies, and supporting material for comprehensive antenatal and postnatal care. The objective in the initial phase was to develop evidence-based provincial guidance to address PMTCT, including antiretroviral regimes, involvement of partners, screening for STIs and $\mathrm{TB}$, and monitoring of anemia and fetal growth. The guidelines were mainly designed to ensure uncomplicated pregnancies among women being followed at the primary care level. The draft, developed through a participatory process involving all stakeholders, incorporated lessons learned from the South Africa FANC intervention as well as findings from other research on maternal care. Pilot testing and distribution of the final guidelines are planned for mid-2008 (Ditlopo et al. 2008).

\section{Is FANC sustainable in sub-Saharan Africa?}

The FRONTIERS studies highlight several challenges for the institutionalization of FANC, including:

- Staff attrition. In South Africa, staff turnover and insufficient involvement of key stakeholders negatively affected clinics' capacity to implement and sustain the reorganized services and the quality of the services (Chege et al. 2005). The problem of staff attrition was also noted in Ghana (ArmarKlemusu et al. 2006).

\section{- Absence of pre-service training.} The sustainability of focused ANC is also constrained by the lack of involvement of pre-service training institutions and professional bodies in the initial design and planning for its introduction and implementation. In Kenya, for example, pre-service training institutions and professional bodies were never involved in the initial design, planning, and subsequent introduction of FANC. In all three countries, the training curricula for ANC in pre-service training institutions remained unchanged.

- Non-involvement of key informants. In South Africa, key informants were closely involved from the conceptual stage through the intervention. Their role was to develop the guidelines and training manuals, conduct training and monitor the intervention process. However, in the other two countries the non-involvement of the professional associations in the initial stages resulted in the absence of articulated standards and full embracement of the concept, especially by supervisors.

\section{- Limited use of FANC services.}

The FANC model is a series of scheduled visits. However, in all three countries the introduction of FANC did not seem to affect the timing of ANC visits by clients. For instance, in South Africa, where the first ANC visit was expected to take place between four and 20 weeks' gestation, about one half of clients attended after 20 weeks, and less than 10 percent used ANC services during the first trimester. There was no significant difference in gestation age at first visit between the intervention and comparison clinics. Only 9 percent of pregnant women in the intervention clinics in Kenya and 24 percent in Ghana made their first visit before 16 weeks, as recommended.

\section{- Funding insufficiency. Inadequate funding to support the deliv- ery of an increased range of services was a common prob- lem in both Kenya and Ghana. In Kenya, the introduction of FANC was largely dependent on support from develop- ment partners. This reliance on external funding subjected}

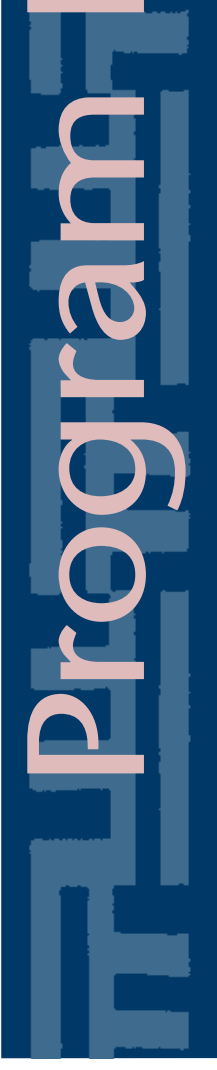


the rollout and routine implementation of FANC to shifting donor priorities.

\section{- Limited implementation.} Implementation of FANC in Ghana remained a responsibility of individual facilities; thus
FANC was an ad-hoc undertaking provided by a few facilities that had the financial capability. However, the creation of new reproductive health policies that pay increased attention to FANC and sector-wide funding in both countries may pave the way for allocation of funds explicitly to FANC, given that it is a priority for achieving the Millennium Development Goals. Whether development partners would agree to such a prioritization remains to be seen.

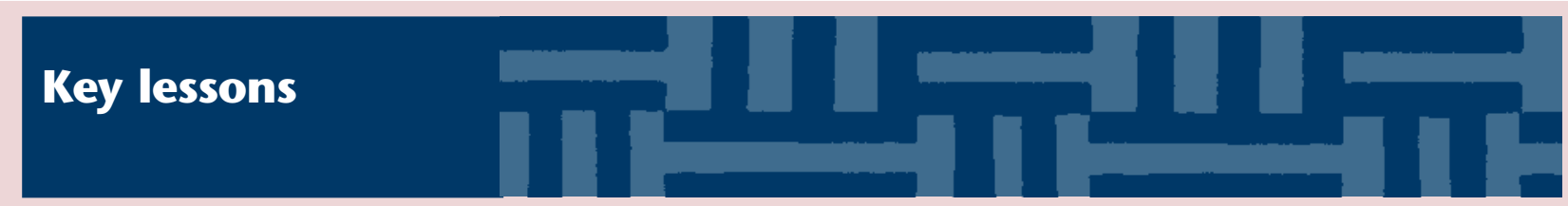

- The introduction of FANC requires:

- Competent providers: modification of pre-service training curricula in ANC and in-service training in ANC for providers and their supervisors.

- Assessment and planning for changes in the drugs, equipment, and supplies needed to provide ANC.

- Infrastructure modifications including redesigning the client care process and physical space available for $\mathrm{ANC}$, and a functioning laboratory.

- Introducing FANC relies heavily on training staff in new ways of organizing and providing services. Given the high staff attrition in subSaharan Africa, it is critical to develop and use training and supervisory strategies that are explicitly designed to address relatively rapid rates of staff turnover. Ideally this would be through pre-service training. In the short term this may mean developing the capacity of all clinic staff, or of the supervisor responsible for monitoring ANC services in the clinic, to ensure that if a trained staff member leaves, the replacement staff member either has the same technical competence, or undergoes immediate training in the ANC model being implemented at that clinic.

- FANC is a scheduled service, and when clients do not adhere to the recommended timing, the very purpose of the service is challenged. Much still needs to be done to make compliance with the timing of FANC visits more feasible. It is also clear that what induces pregnant women to change their ANC service utilization may be more than just a reduction in the number of visits.
Sustainability of the FANC package is contingent upon:

- Continued availability of funding targeted for strengthening ANC services.

- Increased equipment and supplies needed to offer these services at clinics providing ANC.

- Training providers so that they are fully competent in all the component services, and able to offer them in an integrated fashion.

- Ensuring that supervisors are able to support and enable providers to deliver integrated, comprehensive ANC services.

- Communicating the new regimen of services and their timing to the general public so that ANC attendance is initiated earlier and in accordance with the four-visit schedule. 


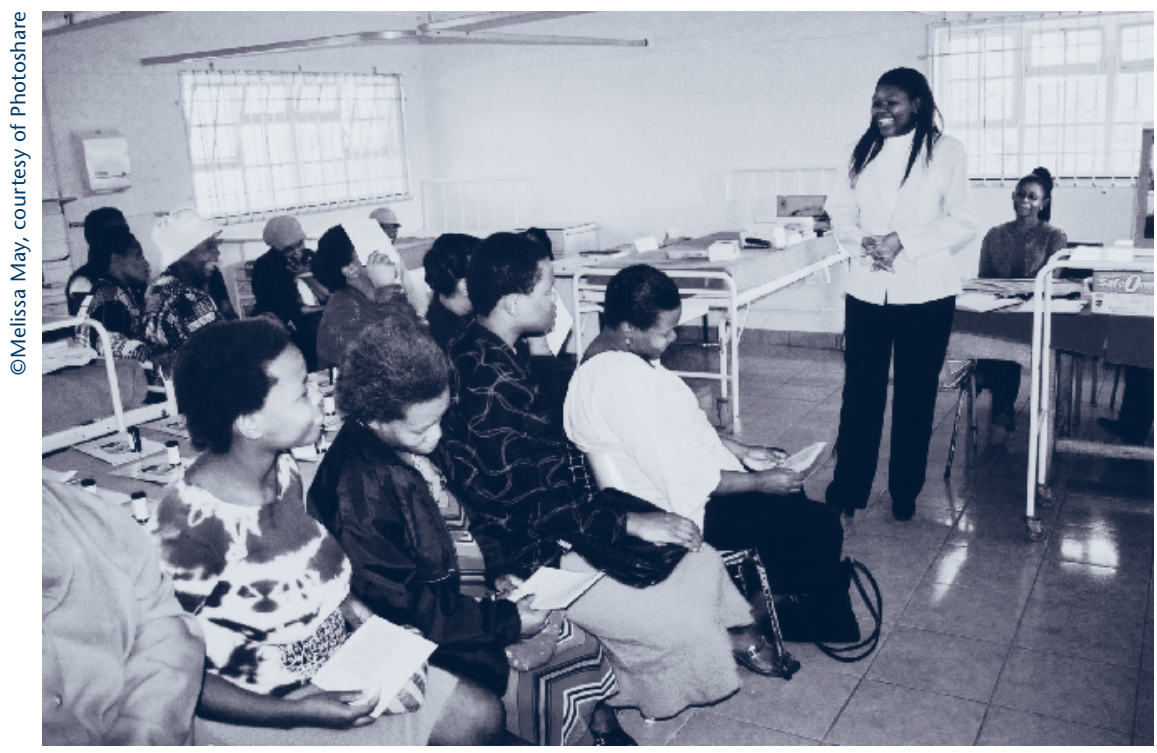

An antenatal counseling session in Durban, South Africa.

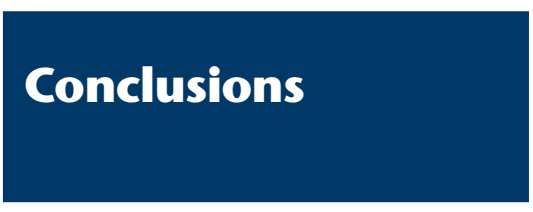

It is feasible and acceptable to clients and providers to introduce FANC into clinics in subSaharan Africa. Its introduction can result in improved quality of care. However, the quality of care already provided is extremely low in all three countries and the FANC interventions did not succeed in raising the levels to acceptable standards. The strengthening and sustainability of FANC in sub-Saharan Africa require explicit policy direction, resource allocation for pre- and in-service training and facility improvements, and coordinated implementation and support. The process of stimulating changes in ANC service delivery requires consultation with and inclusion of key actors, notably the pre-service training institutions and professional bodies, to ensure institutionalization and standardization of focused ANC training and supervision. Also curricula and training materials need to be updated so that FANC is presented as a comprehensive and integrated service, rather than an aggregation of services that a provider may or may not be able to offer.

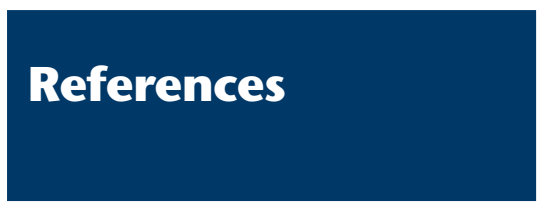

Armar-Klemusu, M. et al. 2006. "Acceptability and feasibility of introducing the WHO focused antenatal care package in Ghana," FRONTIERS Final Report. Washington, DC: Population Council.

Birungi, Harriet and W. Onyango-Ouma. 2006. "Acceptability and sustainability of the WHO focused antenatal care package in Kenya," FRONTIERS Final Report. Washington, DC: Population Council.

Chege, J. et al. 2005. "Feasibility of introducing a comprehensive integrated package of antenatal care services in rural public clinics in South Africa," FRONTIERS Final Report. Washington, DC: Population Council.

Ditlopo, Prudence et al. 2008. "Developing comprehensive and evidence-based policy and guidelines for antenatal and postnatal care in KwaZuluNatal," FRONTIERS Final Report. (In press.)

Villar, J. et al. 2001. "WHO antenatal care randomized trial for the evaluation of a new model of routine antenatal care," The Lancet 357: 1565-1570.

World Health Organization (WHO). 2001. WHO Antenatal Care Randomized Trial: Manual for the Implementation of the New Model. Geneva: WHO. 
The Population Council conducts research worldwide to improve policies, programs, and products in three areas: HIV and AIDS; poverty, gender, and youth; and reproductive health.

The Frontiers in Reproductive Health Program (FRONTIERS) applies systematic research techniques to improve delivery of family planning and reproductive health services and influence related policies. FRONTIERS is funded by the U.S. Agency for International Development (USAID) and led by the Population Council in collaboration with Family Health International.

Frontiers in Reproductive Health Program (FRONTIERS) Population Council 4301 Connecticut Avenue, NW, Suite 280

Washington, DC 20008

Telephone: (202) 237-9400

Facsimile: (202) 237-8410

E-mail: publications@popcouncil.org www.popcouncil.org/frontiers

This publication is made possible by the generous support of the American people through the United States Agency for International Development (USAID) under the terms of Cooperative Agreement No. HRN-A-0098-00012-00. The contents are the responsibility of the FRONTIERS Program and do not necessarily reflect the views of USAID or the United States Government.

\section{(C) 2008 The Population Council, Inc.}

This publication may be reproduced in whole or in part without permission of the Population Council provided full source citation is given and the reproduction is not for commercial purposes. 